\title{
In-hospital Emergencies Versus Out-of-hospital Emergencies Admitted to ICU: Is the Outcome Different? An Observational Study
}

\section{Emi Cauchois}

Assistance Publique - Hôpitaux de Marseille: Assistance Publique Hopitaux de Marseille Jérémy Bourenne

Assistance Publique - Hôpitaux de Marseille: Assistance Publique Hopitaux de Marseille Audrey Le Saux

Assistance Publique - Hôpitaux de Marseille: Assistance Publique Hopitaux de Marseille

Fouad Bouzana

Assistance Publique - Hôpitaux de Marseille: Assistance Publique Hopitaux de Marseille

Antoine Tilmont

Assistance Publique - Hôpitaux de Marseille: Assistance Publique Hopitaux de Marseille

Charlotte Allez

Assistance Publique - Hôpitaux de Marseille: Assistance Publique Hopitaux de Marseille

Vanessa Pauly

Assistance Publique - Hôpitaux de Marseille: Assistance Publique Hopitaux de Marseille

Marc Gainnier

Assistance Publique - Hôpitaux de Marseille: Assistance Publique Hopitaux de Marseille

Julien CARVELLI ( $\sim$ Julien.CARVELLI@ap-hm.fr)

Assistance Publique - Hôpitaux de Marseille: Assistance Publique Hopitaux de Marseille https://orcid.org/0000-0003-1305-9805

\section{Research}

Keywords: intensive care unit, in-hospital emergency, rapid response team, medical emergency team

Posted Date: November 19th, 2020

DOI: https://doi.org/10.21203/rs.3.rs-109006/v1

License: (1) (1) This work is licensed under a Creative Commons Attribution 4.0 International License. Read Full License 


\section{Abstract}

Background: Rapid Response Systems (RRS) are now commonly implemented throughout hospital health systems to manage in-hospital emergencies (IHE). There is limited data on characteristics and outcomes of such patients admitted to an intensive care unit (ICU). The goal was to determine whether the hospital mortality of ICU patients was different depending on their admission pathway: in-hospital via rapid response teams (RRT), or out-of-hospital emergencies (OHE) via prehospital emergency medical systems.

Results: Out of 422 ICU admissions (Timone University Hospital ICU), 241 patients were retrospectively (2019-2020) included: 74 IHE versus 167 OHE. In-hospital mortality rates did not differ between both cohorts $(n=31(42 \%)$ vs. $63(39 \%)$ respectively, NS). IHE patients were older and had more comorbidities (immunosuppression and ongoing malignancy). OHE patients had more severe organ failures at presentation with more frequent mechanical ventilation support. Independent global hospital mortality risk factors were ongoing malignancy (OR = 10.4 [2.7-40], $p<0.001)$, SAPS II (OR = 1.05 [1.03-1.08], $p<$ $0.0001)$ and SOFA scores $(O R=1.14$ [1.01-1.3], $p<0.05)$, hemorrhagic stroke as admission diagnosis (OR $=8.4[2.7-26], p<0.001)$, and arterial lactate on arrival $(O R=1.11[1.03-1.2], p<0.01)$.

Conclusion: This study provides a thorough and comprehensive analysis of characteristics and outcomes of ICU admissions following a mature rapid response activation system, compared to the "conventional" out-of-hospital admission pathway. Despite the more vulnerable background of IHE patients, hospital mortality does not differ, supporting the use of early RRS to identify deteriorating ward patients.

\section{Take-home Message}

Hospital mortality does not differ between in-hospital emergencies admitted to intensive care unit and conventional out-of-hospital admissions, supporting the use of early rapid response systems and the importance of early intensive care unit admission.

\section{Background}

The goal of intensive care units (ICU) is to manage patients presenting one or more organ failures with two major admission pathways. On the one hand, healthcare facilities or investigation wards, otherwise known as in-hospital emergencies (IHE). On the other hand, and more frequently, patients become acutely unwell outside a healthcare institution: they are called out-of-hospital emergencies (OHE). The prognosis of ICU patients may be different depending on where the life-threatening emergency occurred: in or out of hospital. Even if past studies suggest that the IHE mortality rate in ICU is higher than the all-cause mortality rate (1-4), little data is available.

Hospitalized patients have a certain number of acute diseases that weaken their health status. One or more chronic diseases often worsen the global outcome. Their condition can be considered as worse or more vulnerable than the rest of the population. However, hospital wards guarantee a close monitoring 
and rapid care. As a matter of fact, in France, the organization of IHE is led by an expert recommendation $(5,6)$. It relies on a medical team available $24 / 7$, known as the medical emergency team (MET) or rapid response team (RRT) (7). This management has significantly reduced in-hospital cardiac arrests and mortality in hospitalized patients (8-12).

OHE are subject to a more random management, depending on the medical response delay as well as the conditions of social environment. In France, the OHE are transported by prehospital emergency medical systems, and can transit in the emergency room (ER) before ICU admission.

The goal of this study is to compare the hospital mortality of ICU patients admitted after an IHE or an $\mathrm{OHE}$ and to define specific prognostic factors.

\section{Methods}

This is a retrospective and monocentric cohort study performed from May 2019 to March 2020 in the ICU of Timone University Hospital (Marseille, France). All adult patients (over 18 years) admitted to the ICU were examined for eligibility. Adult patients admitted following a call for IHE were enrolled in the IHE group. Patients admitted following the intervention of the prehospital emergency medical system outside a healthcare institution were enrolled in the OHE group. These patients were either directly admitted to ICU or transited for less than 6 hours in the ER. In the IHE group, patients admitted to the hospital less than 24 hours before the call were excluded as it could imply an under-estimation of the initial severity. Elective surgical patients were excluded because of the absence of comparability in the OHE cohort. In the OHE group, patients admitted for severe trauma, intentional overdose and refractory cardiac arrest were excluded for the same reason. In the OHE group, patients who had been hospitalized 3 months or less prior to their current stay were also excluded because they were considered too recently back home. The ICU of Timone University Hospital of Marseille (10 beds) provides a 24/7 management of the IHE of 121 medical ward beds as well as the medical imagery wards. 500 patients are admitted on average per year (100 IHE vs. 400 OHE). The representative of the Commission on Data Processing and Freedom (MR003 research \#2020-81) was notified about this study. We compared characteristics of both groups (IHE versus $\mathrm{OHE}$ ) using univariate statistical test: $\mathrm{Khi}^{2}$ or Fisher exact test for qualitative variables and t-test for quantitative ones. Qualitative variables are resumed by counts and percentages whereas quantitative ones by medians and $25 \%$ and $75 \%$ interquartile ranges (IQR; $25 \%-75 \%$ ). To analyze if type of admission (IHE or OHE) was independently associated with hospital mortality, we performed a multivariate logistic regression analysis with adjustment on other factors. To do so, we first led univariate analysis of mortality with different variables and then we introduced into the multivariate model variables whose $\mathrm{p}$ value was less than 0,20 in the univariate analysis. We then performed a stepwise backward elimination of variables to conserve factors associated with mortality with a p-value less than 0.05 ; type of admission was forced into the model. Results of multivariate analysis were presented using Odds Ratios $(\mathrm{OR})$ and their $95 \%$ Confidence Interval $(\mathrm{Cl})$. Analysis were performed using the SAS ${ }^{\circledR}$ software, version 9.4 , and the threshold for statistical significance was defined at alpha $=0.05$. 


\section{Results}

During the study period, 422 patients were admitted to the ICU (Fig. 1). A total of 74 patients met the inclusion criteria in the IHE group, and 167 in the OHE group ( $N=241)$.

\section{IHE versus OHE patients}

Characteristics of patients in both groups are presented in Table 1. ICU mortality (IHE: $n=26(35 \%)$ vs. OHE: $n=58(35 \%), N S$ ) and in-hospital mortality (IHE: $n=31(42 \%)$ vs. OHE: $n=63(39 \%), N S$ ) were not different between IHE and OHE patients. IHE patients were older (66 year. [58-75] vs. 63 [52-71], $p<0.05$ ) with male predominance $(n=54(74 \%)$ vs. $n=99(59 \%), p<0.05)$. Only $50 \%(n=37)$ were considered as independent in activities of daily living before hospitalization (vs. OHE: $86 \%(n=143), p<0.0001)$. Patients in both groups had the same medical background and comorbidities except for two conditions more frequently seen in the IHE group: immunosuppression ( $n=18(24 \%)$ vs. OHE: $n=7(4 \%), p<0.001)$ and ongoing malignancy $(n=19(26 \%)$ vs. $n=2(1 \%), p<0.001)$. Causes of ICU admission did not differ between the two groups except for cardiac arrest (OHE: $n=51(31 \%)$ vs. IHE: $n=11(15 \%), p<0.05$ ) and hemorrhagic stroke (OHE: $n=21(13 \%)$ vs. IHE: $n=1(1 \%), p<0.01)$ more frequent in the OHE group. No difference was found in each sub-category of shock (septic, hemorrhagic, cardiogenic, other), respiratory failure (pneumonia, ARDS, acute left ventricular failure, other), or low Glasgow Coma Scale (ischemic stroke, seizure, central nervous system infection, other). There was an iatrogenic component to $20 \%$ ( $n=$ $15)$ of the IHE deteriorations (vs. OHE: $6 \%(n=10), p<0.001)$ and $18 \%(n=13)$ for hospital-acquired infection (vs. OHE: $0.6 \% \mathrm{n}=(1), \mathrm{p}<0.001)$. Sepsis-related Organ Failure Assessment (SOFA) score and Simplified Acute Physiology Score II (SAPS II) were lower in the IHE cohort (SOFA: 7 [4-11] vs. 8 [5-11] SAPS II: 43 [36-64] vs. 51 [38-65], NS). We found no significant differences between time of admission and most of the biochemistry results upon arrival in the ICU (Supplementary Table 1). Arterial lactate level was significantly lower in the IHE group $(1.9 \mathrm{mmol} / \mathrm{L}[1.1-3.8]$ vs. OHE: $2.2[1.4-6.3], p<0.05)$ and arterial pH was significantly higher (7.40 [7.29-7.45] vs. 7.33 [7.19-7.41], $p<0.01)$. The other three biochemical differences were a more pronounced anemia in the IHE cohort (hemoglobin $=10.2 \mathrm{~g} / \mathrm{dL}[8,6-$ 12.5] vs. OHE: 12.1 [10.8-13.7], $p<0.001)$, higher venous bicarbonate $(20.5 \mathrm{mmol} / \mathrm{L}$ [17-23.5] vs. 19.5 [14.8-22.1), $\mathrm{p}<0.05)$, and higher levels of serum bilirubin ( $12 \mathrm{mmol} / \mathrm{L}(6-19)$ vs. $8(5-15), \mathrm{p}<0.005)$. In terms of organ replacement therapies initiated, the two groups significantly differed. $66 \%(n=46)$ of IHE received mechanical ventilation versus $88 \%$ of $\mathrm{OHE}(n=147, p<0.001)$ and the length of their ventilatory support was lower ( 2 days [1-5] vs. OHE: 3 [2-7], $p<0.05)$. IHE stayed less time in the ICU (3 days [1-5] vs. OHE: 4 [2-7], p < 0.05), whereas their total hospital stay was much longer (20 days [10-37] vs. 10 [420], $p<0.0001$ ). 
Table 1

Patient characteristics according to their admission pathway: IHE versus OHE

\begin{tabular}{|c|c|c|c|}
\hline & $\begin{array}{l}\text { IHE } \\
n=74\end{array}$ & $\begin{array}{l}\text { OHE } \\
n=167\end{array}$ & $p$ \\
\hline Age, years & $66[58-75]$ & $63[52-71]$ & $<0.05$ \\
\hline Gender (male), n(\%) & $55(74)$ & $99(59)$ & $<0.05$ \\
\hline \multicolumn{4}{|l|}{ Comorbidities, n(\%) } \\
\hline Diabetes mellitus & $25(34)$ & $37(22)$ & NS \\
\hline Cardiovascular disease & $45(61)$ & $87(52)$ & NS \\
\hline Chronic kidney failure & $6(8)$ & $8(5)$ & NS \\
\hline Cirrhosis & $5(7)$ & $4(2)$ & NS \\
\hline Severe COPD or chronic respiratory failure & $6(8)$ & $13(8)$ & NS \\
\hline Chronic heart failure & $3(4)$ & $4(2)$ & NS \\
\hline Ongoing malignancy & $19(26)$ & 2(1) & $<0.001$ \\
\hline Immunosuppression & $18(24)$ & $7(4)$ & $<0.001$ \\
\hline Independant in activities of daily living & $37(50)$ & $143(86)$ & $<0.0001$ \\
\hline \multicolumn{4}{|l|}{ Admission, $\mathrm{n}(\%)$} \\
\hline Time of admission (working hours) & $36(49)$ & $60(36)$ & NS \\
\hline \multicolumn{4}{|l|}{ Cause of admission } \\
\hline Cardiac arrest & 11(15) & $51(31)$ & $<0.05$ \\
\hline Shock & $29(39)$ & $44(26)$ & NS \\
\hline Respiratory failure & $20(27)$ & $27(16)$ & NS \\
\hline Neurological failure & 14(19) & $45(27)$ & NS \\
\hline Ischaemic stroke & $2(3)$ & $3(2)$ & NS \\
\hline Hemorrhagic stroke & $1(1)$ & 21(13) & $<0.01$ \\
\hline latrogenic component & $15(20)$ & $10(6)$ & $<0.001$ \\
\hline Hospital-acquired infection & 13(18) & $1(0.6)$ & $<0.0001$ \\
\hline
\end{tabular}

IHE: In-Hospital Emergencies, OHE: Out-of-Hospital Emergencies, COPD: Chronic Obstructive Pulmonary Disease, SOFA: Sepsis-related Organ Failure Assessment, SAPS II: Simplified Acute Physiology Score II, NIV: Non-Invasive Ventilation, HFNO: High Flow Nasal Oxygen, WSLT: Withdrawal of Life Sustaining Therapies, ICU: Intensive Care Unit. Variables are presented as medians [IQR; $25 \%-75 \%$ ]. 


\begin{tabular}{|c|c|c|c|}
\hline & $\begin{array}{l}\text { IHE } \\
n=74\end{array}$ & $\begin{array}{l}\text { OHE } \\
n=167\end{array}$ & $p$ \\
\hline \multicolumn{4}{|l|}{ Severity Assessment } \\
\hline SOFA & $7[4-11]$ & $8[5-11]$ & NS \\
\hline SAPS II & $43[36-64]$ & $51[38-65]$ & NS \\
\hline \multicolumn{4}{|l|}{ Biochemistry } \\
\hline Arterial pH & $7.40[7.29-7.45]$ & $7.33[7.19-7.41]$ & $<0.01$ \\
\hline Arterial lactate, $\mathrm{mmol} / \mathrm{L}$ & $1.9[1.1-3.8]$ & $2.2[1.4-6.3]$ & $<0.05$ \\
\hline \multicolumn{4}{|l|}{ Organ replacement therapies } \\
\hline \multicolumn{4}{|l|}{ Ventilatory support } \\
\hline NIV, n(\%) & $11(15)$ & $29(17)$ & NS \\
\hline HFNO, n(\%) & $13(18)$ & $37(22)$ & NS \\
\hline Mechanical ventilation, n(\%) & $46(62)$ & 147(88) & $<0.001$ \\
\hline Length of ventilatory support, days & $2[1-5]$ & $3[2-7]$ & $<0.05$ \\
\hline \multicolumn{4}{|l|}{ Hemodynamic support } \\
\hline Catecholamines, n(\%) & $45(61)$ & $95(57)$ & NS \\
\hline Dose of Norepinephrine, $\mu \mathrm{g} / \mathrm{kg} / \mathrm{mn}$ & $0.5[0.3-1]$ & $0.6[0.3-1.2]$ & NS \\
\hline Renal replacement therapy, n(\%) & $8(11)$ & $11(7)$ & NS \\
\hline \multicolumn{4}{|l|}{ Outcomes } \\
\hline \multicolumn{4}{|l|}{ Length of stay, days } \\
\hline ICU & $3[1-5]$ & $4[2-7]$ & $<0.05$ \\
\hline Hospital & $20[10-37]$ & $10[4-20]$ & $<0.0001$ \\
\hline \multicolumn{4}{|l|}{ Mortality, n(\%) } \\
\hline ICU & $26(35)$ & $58(35)$ & NS \\
\hline Hospital & $31(42)$ & 63(39) & NS \\
\hline WSLT, n(\%) & & & \\
\hline
\end{tabular}

IHE: In-Hospital Emergencies, OHE: Out-of-Hospital Emergencies, COPD: Chronic Obstructive Pulmonary Disease, SOFA: Sepsis-related Organ Failure Assessment, SAPS II: Simplified Acute Physiology Score II, NIV: Non-Invasive Ventilation, HFNO: High Flow Nasal Oxygen, WSLT: Withdrawal of Life Sustaining Therapies, ICU: Intensive Care Unit. Variables are presented as medians [IQR; $25 \%-75 \%]$. 


\begin{tabular}{|c|c|c|c|}
\hline & $\begin{array}{l}\mathrm{IHE} \\
\mathrm{n}=74\end{array}$ & $\begin{array}{l}\text { OHE } \\
n=167\end{array}$ & $p$ \\
\hline WLST in ICU & $22(30)$ & $40(24)$ & NS \\
\hline Deaths following WLST in ICU & 13(18) & $25(15)$ & NS \\
\hline \multicolumn{4}{|c|}{$\begin{array}{l}\text { IHE: In-Hospital Emergencies, OHE: Out-of-Hospital Emergencies, COPD: Chronic Obstructive } \\
\text { Pulmonary Disease, SOFA: Sepsis-related Organ Failure Assessment, SAPS II: Simplified Acute } \\
\text { Physiology Score II, NIV: Non-Invasive Ventilation, HFNO: High Flow Nasal Oxygen, WSLT: Withdrawal } \\
\text { of Life Sustaining Therapies, ICU: Intensive Care Unit. Variables are presented as medians [IQR; } \\
25 \%-75 \%] \text {. }\end{array}$} \\
\hline
\end{tabular}

\section{Survivors versus non-survivors (in-hospital mortality)}

The demographic and admission characteristics of survivors versus non-survivors are presented in Table 2. Patients alive at hospital discharge were significantly younger (62 year. [51-70] vs. 66 [59-76], p $<0.05)$ with fewer diabetes mellitus $(n=29(20 \%)$ vs. non-survivors: $n=32(34 \%), p<0.05)$ and ongoing cancer $(n=5(3 \%)$ vs. $n=16(17 \%), p<0.001)$. There was no difference between survivors and nonsurvivors for other comorbidities. Patients admitted for cardiac arrest (survivors: $n=22(15 \%)$ vs. nonsurvivors: $n=40(43 \%), p<0.001$ ) and hemorrhagic stroke (survivors, $n=6(4 \%)$ vs. non-survivors, $n=$ $18(19 \%), p=0.001)$ had a higher risk of death. In contrast, patients admitted for acute cardiogenic pulmonary oedema (survivors: $\mathrm{n}=11(8 \%)$ vs. non-survivors: $\mathrm{n}=0, \mathrm{p}<0.05$ ) or epilepsy (survivors: $\mathrm{n}=$ $21(15 \%)$ vs. non-survivors: $n=3(3 \%), p<0.001$ ) were less likely to die. In non-survivors, $40 \%$ of hospital deaths followed a Withdrawal of Life-Sustaining Therapy (WLST) decision. As expected in deceased patients, SOFA and SAPS II scores were higher, biochemistry results (PT, INR, serum creatinine, serum urea, kalemia, arterial $\mathrm{pH}$, arterial lactate, and venous bicarbonate) were more altered (for biochemical variables, see significant results in Table 2, non-significant results are presented in Supplementary Table 2), and organ replacement therapies were more frequent. 
Table 2

Patient characteristics according to in-hospital mortality

\begin{tabular}{|c|c|c|c|}
\hline & $\begin{array}{l}\text { Survivors } \\
n=143\end{array}$ & $\begin{array}{l}\text { Non-survivors } \\
n=94\end{array}$ & $p$ \\
\hline Age, years & $62[51-70]$ & $66[59-76]$ & $<0.05$ \\
\hline \multicolumn{4}{|l|}{ Comorbidities, n(\%) } \\
\hline Diabetes mellitus & $29(20)$ & $32(34)$ & $<0.05$ \\
\hline Cardiovascular disease & $72(50)$ & $58(62)$ & NS \\
\hline Chronic kidney failure & $6(4)$ & $8(9)$ & NS \\
\hline Cirrhosis & $6(4)$ & $2(2)$ & NS \\
\hline Severe COPD or chronic respiratory failure & $10(7)$ & $8(9)$ & NS \\
\hline Chronic heart failure & $3(2)$ & $4(4)$ & NS \\
\hline Ongoing malignancy & $5(3)$ & 16(17) & $<0.001$ \\
\hline Immunosuppression & $12(8)$ & 13(14) & NS \\
\hline Independant in activities of daily living & 109(76) & $84(89)$ & NS \\
\hline \multicolumn{4}{|l|}{ Admission, n(\%) } \\
\hline Time of admission (working hours) & $51(36)$ & $43(48)$ & NS \\
\hline \multicolumn{4}{|l|}{ Cause of admission } \\
\hline Cardiac arrest & $22(15)$ & $40(43)$ & $<0.001$ \\
\hline Shock & $50(35)$ & $23(24)$ & NS \\
\hline Respiratory failure & $34(24)$ & $9(10)$ & NS \\
\hline Acute cardiogenic pulmonary oedema & $11(8)$ & 0 & $<0.05$ \\
\hline Neurological failure & $37(26)$ & $22(23)$ & NS \\
\hline Epilepsy & $21(15)$ & $3(3)$ & $<0.001$ \\
\hline Hemorrhagic stroke & $6(4)$ & 18(19) & 0.001 \\
\hline latrogenic component & 14(10) & $11(12)$ & NS \\
\hline
\end{tabular}

COPD: Chronic Obstructive Pulmonary Disease, SOFA: Sepsis-related Organ Failure Assessment, SAPS II: Simplified Acute Physiology Score II, PT: Prothrombin Time, INR: International Normalized Ratio, NIV: Non-Invasive Ventilation, HFNO: High Flow Nasal Oxygen, WSLT: Withdrawal of Life Sustaining Therapies, ICU: Intensive Care Unit. Variables presented as medians [IQR; 25\%-75\%]. 


\begin{tabular}{|c|c|c|c|}
\hline & $\begin{array}{l}\text { Survivors } \\
n=143\end{array}$ & $\begin{array}{l}\text { Non-survivors } \\
\mathrm{n}=94\end{array}$ & $p$ \\
\hline SOFA & $7[4-10]$ & $9[7-12]$ & $<0.001$ \\
\hline SAPS II & $42[33-52]$ & $63[52-74]$ & $<0.001$ \\
\hline \multicolumn{4}{|l|}{ Biochemistry } \\
\hline PT, \% & 78 [63-95] & $68[48-80]$ & 0,001 \\
\hline INR & $1.16[1.03-1.35]$ & $1.29[1.16-1.64]$ & $<0.001$ \\
\hline Serum creatinine, $\mu \mathrm{mol} / \mathrm{L}$ & $88[63-126]$ & $114[74-144]$ & $<0.05$ \\
\hline Serum urea, $\mathrm{mmol} / \mathrm{L}$ & $7.3[4.8-10.8]$ & $8.3[6.3-15.3]$ & $<0.05$ \\
\hline Kalemia, mmol/L & $3.8[3.5-4.3]$ & $4.3[3.6-4.9]$ & $<0,001$ \\
\hline Arterial pH & $7.38[7.30-7.44]$ & $7.27[7.12-7.38]$ & $<0,001$ \\
\hline Arterial lactate, $\mathrm{mmol} / \mathrm{L}$ & $1.9[1.2-3.5]$ & $3.5[1.6-10]$ & $<0,001$ \\
\hline Arterial pCO2, mmHg & $35[29-44]$ & 41 [34-53] & $<0,001$ \\
\hline Venous bicarbonate, $\mathrm{mmol} / \mathrm{L}$ & $20.4[17.1-22.6]$ & $17.5[14.1-22.6]$ & $<0,05$ \\
\hline \multicolumn{4}{|l|}{ Organ replacement therapies } \\
\hline \multicolumn{4}{|l|}{ Ventilatory support } \\
\hline NIV, n(\%) & $31(22)$ & $7(7)$ & $<0.05$ \\
\hline HFNO, n(\%) & $37(26)$ & 11(12) & $<0.05$ \\
\hline Mechanical ventilation, n(\%) & 101(71) & $83(88)$ & $<0.01$ \\
\hline Length of ventilatory support, days & $2[1-5]$ & $3[1-7]$ & NS \\
\hline \multicolumn{4}{|l|}{ Hemodynamic support } \\
\hline Catecholamines, n(\%) & $67(47)$ & $65(69)$ & 0.001 \\
\hline Dobutamine, n(\%) & $8(6)$ & 14(15) & $<0.05$ \\
\hline Dose of Norepinephrine, $\mu \mathrm{g} / \mathrm{kg} / \mathrm{mn}$ & $0.4[0.25-0.71]$ & $0.7[0.4-1.42]$ & 0.001 \\
\hline Renal replacement therapy, $n(\%)$ & $7(5)$ & $12(13)$ & $<0.05$ \\
\hline
\end{tabular}

COPD: Chronic Obstructive Pulmonary Disease, SOFA: Sepsis-related Organ Failure Assessment, SAPS II: Simplified Acute Physiology Score Il, PT: Prothrombin Time, INR: International Normalized Ratio, NIV: Non-Invasive Ventilation, HFNO: High Flow Nasal Oxygen, WSLT: Withdrawal of Life Sustaining Therapies, ICU: Intensive Care Unit. Variables presented as medians [IQR; 25\%-75\%]. 


\begin{tabular}{|llll|}
\hline & $\begin{array}{l}\text { Survivors } \\
\mathbf{n}=143\end{array}$ & $\begin{array}{l}\text { Non-survivors } \\
\mathbf{n}=94\end{array}$ & $p$ \\
\hline WLST in ICU & $8(6)$ & $54(27)$ & $<0.001$ \\
\hline COPD: Chronic Obstructive Pulmonary Disease, SOFA: Sepsis-related Organ Failure Assessment, SAPS \\
$\begin{array}{l}\text { II: Simplified Acute Physiology Score II, PT: Prothrombin Time, INR: International Normalized Ratio, } \\
\text { NIV: Non-Invasive Ventilation, HFNO: High Flow Nasal Oxygen, WSLT: Withdrawal of Life Sustaining } \\
\text { Therapies, ICU: Intensive Care Unit. Variables presented as medians [IQR; 25\%-75\%]. }\end{array}$ \\
\hline
\end{tabular}

\section{Independent prognostic factors of in-hospital mortality}

All the potential risk factors contributing to hospital mortality were analyzed. Cardiac arrest, hemorrhagic stroke, diabetes mellitus, ongoing malignancy, mechanical ventilation, catecholamine use, renal replacement therapy and WLST were correlated with hospital mortality on univariate analysis $(p<0.05)$. On the other hand, acute cardiogenic pulmonary edema, epilepsy, and non-invasive ventilation methods were correlated with hospital survival on univariate analysis $(p<0.05)$. On multivariate analysis (Table 3$)$, IHE admission pathway was not an independent risk factor associated with hospital mortality. SAPS II (OR 1.05, 95\% Cl 1.03-1.08, p < 0.0001), SOFA score (OR 1.14, 95\% Cl 1.01-1.3, p< 0.05), hemorrhagic stroke as admission diagnosis (OR 8.4, 95\% Cl 2.7-26, p<0.001), ongoing malignancy (OR 10.4, 95\% Cl 2.7-40, p < 0.001), and arterial lactate on ICU arrival (OR 1.11, 95\% Cl 1.03-1.2, p<0.01) were the independent risk factors associated with hospital mortality.

Table 3

Multivariate analysis of risk factors for in-hospital mortality

\begin{tabular}{|llll|}
\hline & Odds ratio & $95 \% \mathrm{Cl}$ & $\mathbf{p}$ \\
\hline IHE vs. OHE & 1.29 & $0.55-2.99$ & 0.55 \\
\hline SAPS II & 1.05 & $1.03-1.08$ & $<0.0001$ \\
\hline SOFA & 1.14 & $1.01-1.3$ & $<0.05$ \\
\hline Hemorrhagic stroke & 8.4 & $2.7-26$ & $<0.001$ \\
\hline Ongoing malignancy & 10.4 & $2.7-40$ & $<0.001$ \\
\hline Arterial lactate & 1.11 & $1.03-1.2$ & $<0.01$ \\
\hline $\begin{array}{l}\text { IHE: In-Hospital Emergencies, OHE: Out-Of-Hospital Emergencies, SOFA: Sepsis-related Organ Failure } \\
\text { Assessment, SAPS II: Simplified Acute Physiology Score II }\end{array}$ & \\
\hline \multicolumn{4}{|l}{} \\
\hline
\end{tabular}

\section{Discussion}

This present study is the first to compare ICU patients' outcomes regarding their admission pathway: in or out-of-hospital. Despite the inherent bias of a single-center, retrospective study, its strengths include the strict comparability of its patients and their standardized management strategy. It concerns patients 
admitted for medical issues only and excludes patients with very specific ICU prognosis: elective surgical patients, severe trauma, intentional overdose and refractory cardiac arrests.

We found no difference in terms of hospital mortality between these two groups of emergencies while obvious differences describe them. IHE are more vulnerable patients. Indeed, they are older, characterized by much less independence in activities of daily living and more comorbidities, mainly immunosuppression and ongoing malignancy. IHE are mostly admitted for respiratory failures or shock. OHE patients are younger, have less comorbidities and are mostly admitted for cardiac arrest or coma caused by a hemorrhagic stroke. OHE suffer from more severe organ failures at presentation, have more lactic acidosis and more mechanical ventilation. In brief, our study brings out a similar mortality rate in both groups, highlighting more severe patients in the OHE group compared to the more vulnerable patients in the IHE group. Relating to IHE patients, our study underlines the importance of early ICU admission. Indeed, our results suggest that we manage these patients promptly, before they reach the severity of our OHE cohort. $8 \mathrm{IHE}$ patients $(12 \%)$ admitted to the ICU had already showed warning signs leading to a prior call from the ward. Severity scores and hospital mortality in this sub-group are much higher than those in patients immediately managed in ICU after a first call (SAPS II in "prior-call group": 65 [53-82] vs. "first-call" group: 42 [36-59], $p=0.084$; hospital mortality in "prior-call" group: $89 \%(n=7)$ vs. "first-call" group: $36 \%(n=23), p<0.01)$. This data indicates that a delayed response may worsen patient outcome, as shown in a large studies $(13,14)$.

In our study, hospital mortality in the two groups was high: $42 \%$ in the IHE group, 39\% in the OHE group. A recent review of the literature shows an in-hospital mortality rate of $29 \%$ for IHE transferred to ICU. Studies from this review originated from many different countries and rates ranged from 7 to $35 \%$ (15). Another large Australian study reveals a hospital mortality rate of $35 \%$ in the same group of patients (16). In our study, the high median severity scores (SOFA: 7 [4-11] and SAPS II: 43 [36-64]) highlight the validity of an ICU admission. These elements either do not appear or are much lower (17) in other studies. Furthermore, our IHE patients are mostly medical patients. Medical category of admission is proven to be a major predictive factor of mortality in critically ill patients $(18,19)$. Cultural differences, critical care capacity and resources, and whether critical care is deemed justified or futile have great influence on consequent results (20). One must be careful when interpreting such rates. As mentioned earlier, previous studies suggest that hospital mortality rates of patients admitted after RRT review were higher than the overall mortality rates (1-4). However, these studies took place at least 15 years ago, and RRS have improved. Tirkkonen et al. (15) suggest that ICU mortality rates of IHE patients are higher than the overall ICU mortality rates in recent multicentre studies $(21,22)$, but no specific study was yet designed to compare in-hospital and out-of-hospital emergency outcomes.

This study reveals five independent risk factors for hospital mortality: SOFA and SAPS II score, hemorrhagic stroke as admission diagnosis, arterial lactate on ICU arrival, and ongoing malignancy. Our study confirms abundant evidence that lactate concentration is a predictor of mortality (23). The addition of lactate to ICU prognostication has been also shown to improve preexisting scores (24). The first four risk factors for hospital mortality found in our study are not useful decision-aid tools for ICU triage.

Page $11 / 16$ 
Indeed, the MET or ICU physician do not initially know these four elements, when the patient's admission needs to be decided. However, ongoing malignancy is a well-known independent risk factor for hospital mortality in critically ill patients $(25,26)$. In line with recent data, in this population, hospital mortality increases tenfold. Even though new strategies of ICU admissions in cancer patients have been developed according to major recent advances in oncology, METs should bear in mind that ongoing malignancy is a key hospital mortality predictor. Along with age, it appears to be very useful for risk stratification of deteriorating patients in wards and determination of appropriate escalation of care. Our observations cannot be extrapolated to haematological malignancies as only solid cancer patients are represented in our study. Our results encourage strategies of time-limited trials of intensive care for critically ill patients with cancer. Indeed, after a 2 to 4-day trial, with the hindsight of initial severity scores and their progression, it seems appropriate to establish a joint assessment for re-evaluation of goals of therapy and level of care (27).

\section{Conclusion}

This study provides a thorough and comprehensive analysis of characteristics and outcomes of ICU admissions following a mature rapid response activation system, compared to the "conventional" out-ofhospital admission pathway in France. Our study supports the use of early rapid response systems to identify deteriorating ward patients and underlines the importance of early ICU admission, before severe organ failure. Patients with arterial lactate over $2 \mathrm{mmol} / \mathrm{L}$ should easily be admitted. Regarding more vulnerable patients, namely solid cancer patients, multiple organ failure after a 2 to 4 -day trial of intensive care should lead physicians to question the appropriateness of a full-code ICU management.

\section{Abbreviations}

ICU

Intensive Care Units; IHE:In-Hospital Emergencies; OHE:Out-of-Hospital Emergencies; MET:Medical Emergency Team; RRT:Rapid Response Team; RRS:Rapid Response System; ER:Emergency Room; IQR:Interquartile Ranges; OR:Odds Ratio; Cl:Confidence Interval; SOFA:Sepsis-related Organ Failure Assessment; SAPS II:Simplified Acute Physiology Score II; COPD:Chronic Obstructive Pulmonary Disease; WLST:Withdrawal of Life-Sustaining Therapy ; APACHE:Acute Physiology and Chronic Health Evaluation; MPM:Mortality Probability Model

\section{Declarations}

\section{Ethics approval and consent to participate}

This study was notified to the representative of the Commission on Data Processing and Freedom (MR003 research \#2020-81) and no consents were required.

\section{Consent for publication}


Written informed consent was not obtained for publication of these data.

\section{Availability of data and material}

EC had full access to all data in the study and takes responsibility for the integrity of the data and the accuracy of the data analysis.

\section{Competing interests}

The authors declare that they have no competing interests.

\section{Funding}

The authors declare that they received no funding.

\section{Authors' contributions}

JC devised and supervised the study. EC, MG and JC performed research. EC and JC wrote the manuscript. EC is the guarantor for the content of the manuscript, including the data and analysis. VP and MG analyzed the data. EC, JB, ALS, FB, AT, CA, MG and JC took care of patients. All authors read and approved the final manuscript.

\section{Acknowledgments}

None.

\section{References}

1. Goldhill DR, Sumner A. Outcome of intensive care patients in a group of British intensive care units: Crit Care Med. 1998 Aug;26(8):1337-45.

2. Escarce JJ, Kelley MA. Admission source to the medical intensive care unit predicts hospital death independent of APACHE II score. JAMA. 1990 Nov 14;264(18):2389-94.

3. Lundberg JS, Perl TM, Wiblin T, Costigan MD, Dawson J, Nettleman MD, et al. Septic shock: An analysis of outcomes for patients with onset on hospital wards versus intensive care units. Crit Care Med. 1998 Jun;26(6):1020-4.

4. Azoulay E, Adrie C, De Lassence A, Pochard F, Moreau D, Thiery G, et al. Determinants of postintensive care unit mortality: A prospective multicenter study: Crit Care Med. 2003 Feb;31(2):428-32.

5. Jouffroy R, Bobbia X, Gauss T, Bouzat P, Pierre M, ACUTE committee of the French Society of Anaesthesia and Intensive Care Medicine. Process and organisation of in-hospital emergencies in France. Anaesth Crit Care Pain Med. 2018;37(6):629-31.

6. SFAR. Conférence d'experts 2004 - Recommandations pour l'organisation de la prise en charge des urgences vitales intrahospitalières. Réanimation; 2005. 
7. Soar J, Nolan JP, Böttiger BW, Perkins GD, Lott C, Carli P, et al. European Resuscitation Council Guidelines for Resuscitation 2015: Section 3. Adult advanced life support. Resuscitation. 2015 Oct;95:100-47.

8. Chan PS, Jain R, Nallmothu BK, Berg RA, Sasson C. Rapid Response Teams: A Systematic Review and Meta-analysis. Arch Intern Med. 2010 Jan 11;170(1):18-26.

9. Konrad D, Jäderling G, Bell M, Granath F, Ekbom A, Martling C-R. Reducing in-hospital cardiac arrests and hospital mortality by introducing a medical emergency team. Intensive Care Med. 2010 Jan;36(1):100-6.

10. Beitler JR, Link N, Bails DB, Hurdle K, Chong DH. Reduction in hospital-wide mortality after implementation of a rapidresponse team: a long-term cohort study. Crit Care. 2011;15(6):R269.

11. Maharaj R, Raffaele I, Wendon J. Rapid response systems: a systematic review and meta-analysis. Crit Care Lond Engl. 2015 Jun 12;19:254.

12. Jung B, Daurat A, De Jong A, Chanques G, Mahul M, Monnin M, et al. Rapid response team and hospital mortality in hospitalized patients. Intensive Care Med. 2016 Apr;42(4):494-504.

13. Stelfox HT, Bagshaw SM, Gao S. Characteristics and outcomes for hospitalized patients with recurrent clinical deterioration and repeat medical emergency team activation*. Crit Care Med. 2014 Jul;42(7):1601-9.

14. Boniatti MM, Azzolini N, Viana MV, Ribeiro BSP, Coelho RS, Castilho RK, et al. Delayed medical emergency team calls and associated outcomes. Crit Care Med. 2014 Jan;42(1):26-30.

15. Tirkkonen J, Tamminen T, Skrifvars MB. Outcome of adult patients attended by rapid response teams: A systematic review of the literature. Resuscitation. 2017 Mar;112:43-52.

16. Le Guen MP, Tobin AE, Reid D. Intensive Care Unit Admission in Patients following Rapid Response Team Activation: Call Factors, Patient Characteristics and Hospital Outcomes. Anaesth Intensive Care. 2015 Mar;43(2):211-5.

17. Jäderling G, Bell M, Martling C-R, Ekbom A, Bottai M, Konrad D. ICU admittance by a rapid response team versus conventional admittance, characteristics, and outcome. Crit Care Med. 2013 Mar;41(3):725-31.

18. Le Gall JR, Lemeshow S, Saulnier F. A new Simplified Acute Physiology Score (SAPS II) based on a European/North American multicenter study. JAMA. 1993 Dec 22;270(24):2957-63.

19. Zimmerman JE, Kramer AA, McNair DS, Malila FM. Acute Physiology and Chronic Health Evaluation (APACHE) IV: hospital mortality assessment for today's critically ill patients. Crit Care Med. 2006 May;34(5):1297-310.

20. Prin $\mathrm{M}$, Wunsch $\mathrm{H}$. International comparisons of intensive care: informing outcomes and improving standards. Curr Opin Crit Care. 2012 Dec;18(6):700-6.

21. Vincent J-L, Marshall JC, Namendys-Silva SA, François B, Martin-Loeches I, Lipman J, et al. Assessment of the worldwide burden of critical illness: the intensive care over nations (ICON) audit. Lancet Respir Med. 2014 May;2(5):380-6. 
22. Capuzzo M, Volta C, Tassinati T, Moreno R, Valentin A, Guidet B, et al. Hospital mortality of adults admitted to Intensive Care Units in hospitals with and without Intermediate Care Units: a multicentre European cohort study. Crit Care Lond Engl. 2014 Oct 9;18(5):551.

23. Haas SA, Lange T, Saugel B, Petzoldt M, Fuhrmann V, Metschke M, et al. Severe hyperlactatemia, lactate clearance and mortality in unselected critically ill patients. Intensive Care Med. 2016 Feb;42(2):202-10.

24. Andersson P, Frigyesi A. Lactate improves SAPS 3 prognostication. Acta Anaesthesiol Scand. 2018 Feb;62(2):220-5.

25. Puxty K, McLoone P, Quasim T, Sloan B, Kinsella J, Morrison DS. Risk of Critical Illness Among Patients With Solid Cancers: A Population-Based Observational Study. JAMA Oncol. 2015 Nov;1(8):1078-85.

26. Azoulay E, Schellongowski P, Darmon M, Bauer PR, Benoit D, Depuydt P, et al. The Intensive Care Medicine research agenda on critically ill oncology and hematology patients. Intensive Care Med. 2017 Sep;43(9):1366-82.

27. Shrime MG, Ferket BS, Scott DJ, Lee J, Barragan-Bradford D, Pollard T, et al. Time-Limited Trials of Intensive Care for Critically III Patients With Cancer: How Long Is Long Enough? JAMA Oncol. 2016 Jan;2(1):76-83.

\section{Figures}

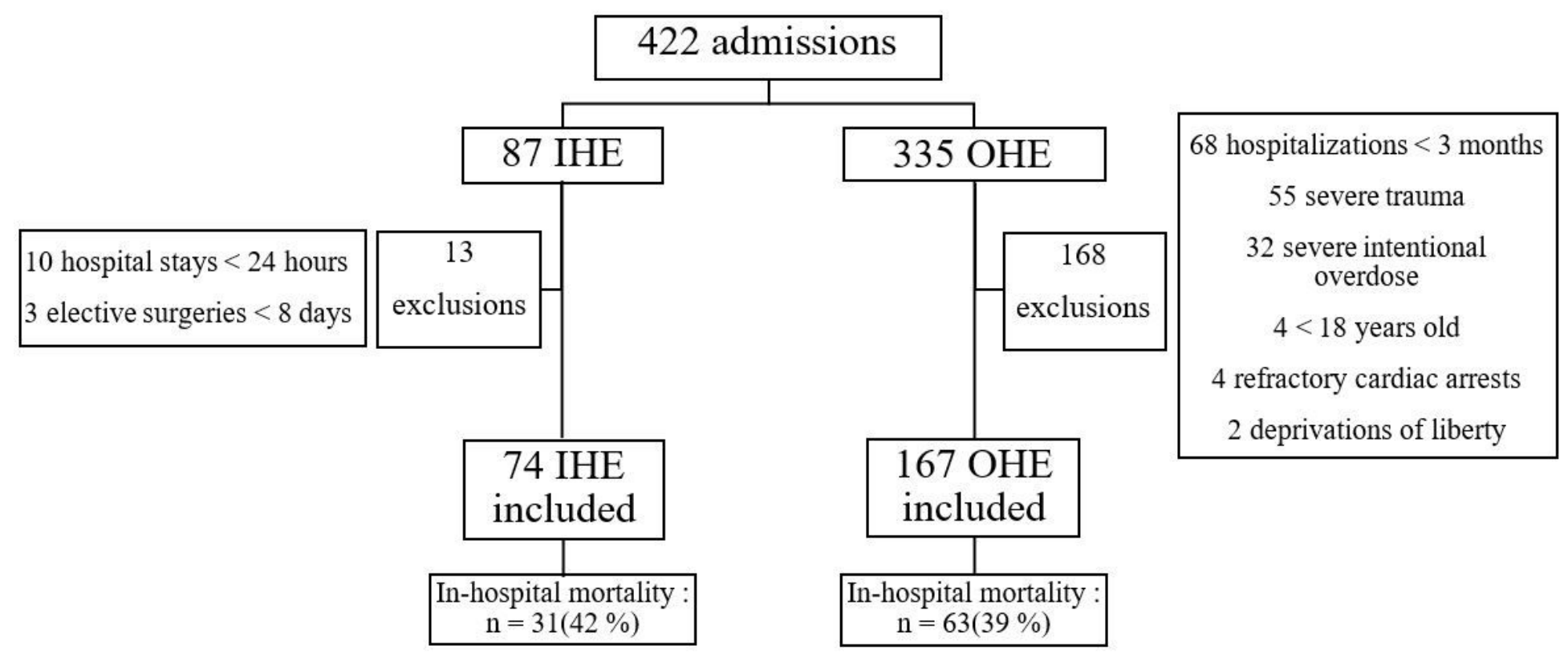

\section{Figure 1}

Flow chart

\section{Supplementary Files}


This is a list of supplementary files associated with this preprint. Click to download.

- SupplementaryTables.docx 